\title{
Probiotic Bifidobacterium longum BB536 Viable Existence at Refrigeration Storage of Fermented Goat Milk Supplemented with Inulin and Different Cereal Bran (Sorghum, Barely and Millet)
}

\author{
Limia Hashim Mohamed, Barka Mohammed Kabeir*, \\ Salma Elghali Mustafa, Salma Elzen Ibraheem and Saeed Abdullah Badahdah
}
Department of Food Science and Technology, College of Agricultural Studies, Sudan University of Science and Technology, Khartoum, Sudan

*Corresponding author

\begin{abstract}
A B S T R A C T
This study was carried out to evaluate viable existence of Bifidobacterium longum BB536 during two weeks refrigeration of fermented goat milk supplemented with inulin and different cereal bran (Sorghum, Barely and Millet). Fermentation mediums were formulated from goat milk supplemented with $10 \%$ inulin and different cereal bran (sorghum, barely and millet). Probiotic strain B. longum BB 536 was used as the starter culture for $12 \mathrm{~h}$ incubation to attain the fermented products. Two weeks refrigeration period was design for the fermented products. Different analyses including: strain BB536 viable count, reducing sugar, physicochemical analysis (TSS, $\mathrm{pH}$, acidity) and moisture were conducted. The maximum viable existence of strain BB 536 throughout refrigeration (two weeks) was in fermented goat milk supplemented with millet bran (lowest reduction of $1.48 \mathrm{CFU} / \mathrm{ml}$ ); whereas, the best existence in the first week was in fermented goat milk supplemented with barely bran $(0.76 \mathrm{CFU} / \mathrm{ml})$. Therefore, the strain existence trend was dependent mainly on both type of fiber source and refrigeration period. Hopefully, the final viable count of strain BB536 in all products was above the minimum number required to presence in probiotic to exert health benefits upon consumption. During refrigeration of fermented products reductions in reducing sugar, TSS and $\mathrm{pH}$; and increases in acidity and moisture were revealed due to the slight strain BB536 enzymatic activities. Therefore, maximum viable existence of strain BB536 in fermented goat milk under refrigeration for two weeks could be achieved by supplementation with millet bran; while better existence in the first week was attainable with barley bran supplementation.
\end{abstract}

Keywords

Bifidobacterium, Goat milk, Cereal bran, Existence, Refrigeration

\section{Introduction}

The word 'probiotic', derived from the Greek language, means 'for life' (Fuller, 1989) and has had many definitions in the past. Definitions such as 'substances produced by protozoa that stimulate the growth of another' or 'organisms and substances that have a beneficial effect on the host animal by contributing to its intestinal microbial balance' were used (Fuller, 1989). These general definitions were unsatisfactory 
because 'substances' include chemicals such as antibiotics. The definition of probiotics has since then been expanded to stress the importance of live cells as an essential component of an effective probiotic. Furthermore, Huis-Veld and Havenaar (1991) broadened the definition of probiotics as being 'a mono- or mixed culture of live microorganisms which, applied to man or animal (e.g. as dried cells or as a fermented product), beneficially effects the host by improving the properties of the indigenous microflora. This definition implies that probiotic products, for example fermented milk, contain live microorganisms and improve the health status of the host by exerting beneficial effects in the gastrointestinal tract.

Bifidobacterium longum is one of the Bifidobacterium species found mainly in human feces and it considered as the most common species being found both in infant and adult. Potential benefits from consumption of $B$. longumBB536 include: antagonistic action toward intestinal pathogens, improved lactose utilization, anticarcinogenic action and control of serum cholesterol levels (Kojima et al., 1996; Namba et al., 2003). Thus, there is still considerable interest in incorporating this probiotic Bifidobacterium into food. Nevertheless, probiotic strains, particularly Bifidobacterium are rarely used outside the diary based industry. Together with the scarcity of animal milk in many countries makes it difficult to provide adequate intake of this health promoting probiotic bacteria..

Milks contain, with some exceptions, the nutrients required for the growth and development of the neonate as well as probiotic bacteria. It contains specific proteins, fats designed to be easily digested, most have lactose, minerals, vitamins, and other components which may have important roles in supporting probiotic growth (Jensen et al., 1991).

Goat milk differs from cow or human milk by having better digestibility, higher alkalinity, increased buffering capacity, and certain therapeutic effects that may be useful in medicine and human nutrition. The good acceptability and digestibility of goat milk are important beneficial factors for its inclusion in formulated diets prescribed for children and convalescent people. In many cases, goat milk may be successfully used as substitute for cow milk in the regular diet of allergic individuals (Haenlein, 2003). Thus, fermentation of goat milk with probiotics could further improve its therapeutic properties.

Dietary fibers are part of the plant cell which cannot be digested by the human enzymes. Two various groups of dietary fibers are recognized: soluble and non-soluble dietary fiber. They are remarkable by their solubility in water and show different physiological effects. The benefit of dietary fiber for a healthy diet is widely known. Different diseases, such as constipation, coronary heart diseases and cancer have been correlated to an unhealthy diet, low in dietary fiber (Kohimeler et al., 1993). Dietary carbohydrates like resistance starch, insoluble fiber and soluble fiber that are able to stimulate, specifically the growth of potentially beneficial bacteria, e.g., bifidobacteria at the expense of the more harmful pathogenic microorganisms, are called prebiotics (Kouane et al., 2005). On the other hand, dietary fibers are often characterized by high nutritional quality, as they are able to cure many chronic diseases and improve texture, sensory characteristics, and shelf life of foods. The fast growing food industry will likely generate an ever-growing amount of byproducts including bran, husk, peel, pomace, and other products that are rich 
in dietary fibers (Betoret et al., 2011). Recently, prebiotic effect of different cereal bran (sorghum, barely and millet) on growth of Bifidobacterium longum BB536 during fermentation of goat milk was approved (Mohamed et al., 2020). However, sightseen of their roles during the storage are lacking. Therefore, the objective of this study is to evaluate the existence of strain BB536 in fermented goat milk supplemented with cereal bran and assess its related physiochemical changes during refrigeration storage.

\section{Materials and Methods}

\section{Raw Materials}

Inulin was obtained from A natural Product Company (London, England). Different cereal bran (sorghum, barley and millet) were purchased from a local crops market at central market in Bahri (Khartoum state, Sudan). Goat fresh milk was obtained from the animal farm at Department of Animal Production, College of Agricultural Studies, Sudan University of Science and Technology (Khartoum, Sudan).

\section{Preparation of cereal bran}

Different cereal brans were ground and sieved using appropriate mesh. The resulting powder stored in a dark polyethylene bag at freezer until used.

\section{Preparation of fermentation inoculums}

B. longum BB536 was obtained from the stock culture of microbiology laboratory (Department of Food Science Technology, Collage of Agriculture Studies (SUST). The strain was maintained at $-20{ }^{\circ} \mathrm{C}$ in $20 \%$ glycerol solution. Stock culture was prepared by activation of the strain in skim milk, incubation an aerobically at $37{ }^{\circ} \mathrm{C}$ for $24 \mathrm{~h}$. The obtained culture was reactivated again under the same conditions to prepare enough stock for the experiment. The working culture was prepared by twice successive transformations of stock culture in 10\% sterilized skim milk $\left(121^{\circ} \mathrm{C}\right.$ for $\left.15 \mathrm{~min}\right)$ and incubation at $37{ }^{\circ} \mathrm{C}$ for $24 \mathrm{~h}$.

\section{Growth medium and fermentation conditions}

Growth medium were formulated from goat milk supplemented with $1 \%$ inulin or different cereal bran (sorghum, barely and millet). Formulated medium were sterilized $\left(121^{\circ} \mathrm{C}\right.$ for $\left.15 \mathrm{~min}\right)$ and inoculated with a $3 \%$ active culture working of $B$. longum BB536 followed by incubation at $37{ }^{\circ} \mathrm{C}$ for $24 \mathrm{~h}$.

\section{Enumeration of viable $B$. longum BB536 cell}

MRS medium was used to enumerate $B$. longum BB536 of different fermented products using the plate count technique. Fermented samples were drawn at initial and every $6 \mathrm{~h}$ intervals during fermentation. $1 \mathrm{ml}$ of fermentation broth was diluted in peptone water, followed by plating on Demann Rogosa agar (MRS) supplement with $0.05 \%$ L-cystiene. The plates were incubated unaerobically at $37{ }^{\circ} \mathrm{C}$ for $48 \mathrm{~h}$. The growth was calculated as Colony Forming Unit per $\mathrm{ml}(\mathrm{CFU} / \mathrm{ml})$.

\section{Determination of reducing sugars}

Ten gram of sample was weighted in volumetric flask. The volume of the solution was completed to $100 \mathrm{ml}$ in conical flask. Burrete $(50 \mathrm{ml})$ was filled with the prepared sugar solution. Ten milliliters of sugar solution was transferred into a conical flask containing $10 \mathrm{ml}$ Fehling's solution representing $5 \mathrm{ml}$ of Fehling A $(6.928 \mathrm{gm}$ $\mathrm{CuSo} 4.5 \mathrm{H} 2 \mathrm{O}$ per $100 \mathrm{ml}$ distilled water) and 5 $\mathrm{ml}$ Fehling B (34.6 sodium potassium titrate 
and $10 \mathrm{gm} \mathrm{NaOH}$ per $100 \mathrm{ml}$ distilled water) mixed well and then heated moderately to boiling on an electrical hot plate heater. The liquid was kept boiling for about 2 minutes then 3 drops of methylene blue indicator $(1 \%)$ was added. The titration was then completed by the addition of sugar solution drop by drop until the color of the indicator disappeared and red brick color appeared, then reducing sugar was calculated following Schneider et al., (1982) method.

\section{Determination of titrable acidity}

The titrable acidity (TA) of the different fermented products was determined according to AOAC method (2006). Ten $\mathrm{ml}$ of sample were weighted into a conical flask. Adistilled water was added until the volume in the flask was $150 \mathrm{ml}$. The sample was then vigorously agitated and filtered. Twenty five milliliters of the filtrate were pipetted into porcelain dish, five drops of phenolphthalein added, and the sample was titrated against $0.1 \mathrm{~N} \mathrm{NaOH}$ till a faint pink colour that lasted for at least 30 seconds was obtained; then acidity of different products was calculated.

\section{Determination of total soluble solids (TSS)}

Total soluble solids (TSS) of the fermented products were determined at room temperature using digital refractometer with degree $\mathrm{Brix}^{\mathbf{0}}$ scale $0-100$ according to AOAC (1990) method.

\section{Determination of $\mathrm{pH}$ value}

The $\mathrm{pH}$ value of the different fermented products was determined using a $\mathrm{pH}$-meter (model HI 8521 microprocessor bench $\mathrm{PH} / \mathrm{MV} / \mathrm{C}$ meter, Romania). Two standard buffer solution of $\mathrm{pH} 4.00$ and 7.00 were used for calibration of the $\mathrm{pH}$ meter at room temperature. The $\mathrm{pH}$ meter was allowed to stabilize for one minute and then the $\mathrm{pH}$ of the fermented products samples was directly measured.

\section{Determination of moisture content}

Moisture was determined according to the modified method of AOAC (1990). Five grams of the sample was weight using in sensitive balance, after weighting the empty dishes and then transferred to an oven (KatNR.2851, Electrohelios, Sweden) at $105 \pm$ $0.1^{\circ} \mathrm{C}$ for 6 hours. Afterwards, the dish with sample was transferred to dessicator and allows to cool to room temperature before reweighting to calculated moisture.

\section{Statistical analysis}

One- way an ANOVA test was performed to examine significant differences between normally distributed data of replicated independent runs. Probability level of less than 0.05 was considered significant $(\mathrm{p}<0.05)$. All data were analyzed using vision 17 MINITAB statistical software for windows (2010).

\section{Results and Discussion}

The viable counts of Bifidobacterium longum BB536 log (CFU/ ml) during refrigeration storage of fermented goat milk supplemented with inulin and different cereal bran

Table 1 shows the viable counts of B. longum BB536 during refrigeration storage of different formulated goat milk supplemented with inulin and different cereal bran (Sorghum, Barely and Millet). The survival of probiotic bacteria in fermented dairy bioproducts depends on such varied factors as the strains used, interaction between species present, culture conditions, chemical composition of the fermentation medium (e.g. carbohydrate source), final acidity, milk solids 
content, availability of nutrients, growth promoters and inhibitors, concentration of sugars (osmotic pressure), dissolved oxygen (especially for Bifidobacterium sp.), level of inoculation, incubation temperature, fermentation time and storage temperature. Referring to the result in Table 1, there were significant $(\mathrm{p}<0.05)$ reductions in $B$. longum $B B 536$ viable count in all fermented samples at refrigeration. With regard to total reduction of strain BB536throughout the storage period (two weeks), the highest value was in goat milk supplemented with barley bran (1.92 CFU /ml), followed by sorghum bran(1.83 $\mathrm{CFU} / \mathrm{ml})$, inulin $(1.81 \mathrm{CFU} / \mathrm{ml})$ and then millet bran $(1.24 \mathrm{CFU} / \mathrm{ml})$ in descending order (Table 1). The maximum rate of reduction in the first week of the refrigeration storage was in in fermented goat milk supplemented with millet bran (1.48CFU $/ \mathrm{ml}$ ); while the lowest was in in fermented goat milk supplemented with barely bran (0.76 CFU /ml). Nevertheless, the trend of reduction based on fiber source differed in the second week. It was revealed highest strain BB536 reduction in goat milk supplemented with sorghum bran $(1.57 \mathrm{CFU} / \mathrm{ml})$, but the lowest reduction was in goat milk supplemented with millet bran $(0.44 \mathrm{CFU} / \mathrm{ml})$ as presented in Table 1. Therefore, the trend of strain BB 536 reduction throughout the refrigeration period in fermented goat milk supplemented with different fiber was dependent mainly on its source type. For instant, the highest total reduction was in fermented goat milk supplemented with barley bran; whereas, the maximum reductions in the first and second week refrigeration were in fermented goat milk supplemented with millet bran and sorghum bran, respectively. Hopefully, the final viable count of strain BB536 in fermented goat milk after two weeks refrigeration storage was above the minimum number required to presence in probiotic to exert health benefits upon consumption, which was at least $6 \mathrm{log}$
CFU/ml. Nevertheless, Kabeir et al., (2005) reported that survivability of $B$. longum BB536 under refrigeration storage of fermented Sudanese Medida (Sudanes cereal thin porridge) beverages was not affected for a period of 2 week. While Akalin et al., (2004) noted a significant reduction on B.longum BB46 in yogurt after 1 week refrigeration. Lactate and acetate accumulation caused limitation on growth and survival of Bifidobacterium bifidum, Bifidobacterium breve, and Bifidobacterium longum cultivated in milk (Desjardins et al., 1990). This indicates that the viability of Bifidobacterium in fermented products was dependent on the carrier type and $\mathrm{pH}$ of the fermented products during the storage. Overall, most strains of Bifidobacterium are sensitive to $\mathrm{pH}$ values below 4.6. Therefore, for practical application, a $\mathrm{pH}$ value of the final product must be maintained above 4.6 to prevent the decline of Bifidobacterium populations (Tamime and Robinson, 1985; Modler et al., 1990; Laroia and Martin, 1991). The variances in survival were interpreted by the metabolic activity of Bifidobacterium in different fermented products, which might be affected by the composition and availability of nitrogen and carbon sources in growth media as stated by Chou and Hou (2000).

\section{Reducing sugars during refrigeration storage of fermented goat milk supplemented with inulin and different cereal bran}

Reducing sugars levels of the different fermented goat milk supplemented with inulin and different cereal bran (Sorghum, Barely and Millet) during refrigeration storage was presented in Table 2 . The reductions in sugar were significant $(\mathrm{p}<0.05)$ in all fermented goat milk products (Table 2). The amount of sugar decreases in the first week refrigeration were $0.73,0.50,0.29$ and $0.03 \%$ in fermented goat milk supplemented with barely bran, 
sorghum bran, millet bran and inulin, respectively. On the contrary, reductions in the second week were not following similar trend of the first recording values of 0.28 , $0.21,0.19$, and $0.11 \%$ in fermented goat milk supplemented with inulin, sorghum bran, millet bran and barely bran, respectively. These reduction rates are well correlation values with $\mathrm{pH}$ record present in table 3 .

Table.1 The viable counts of Bifidobacterium longum BB536log (CFU/ ml) during refrigeration storage of fermented goat milk supplemented with inulin and different cereal bran

\begin{tabular}{|c|l|l|l|}
\hline \multirow{2}{*}{$\begin{array}{c}\text { Type of } \\
\text { supplementation }\end{array}$} & \multicolumn{3}{|c|}{ Storage period (weeks) } \\
\cline { 2 - 4 } & $\mathrm{O}($ Initial) & One & Two \\
\hline Inulin & $7.83 \pm 0.16^{\mathrm{a}}$ & $6.98 \pm 1.54$ & $6.02 \pm 0.08$ \\
\hline Sorghum bran & $8.43 \pm 0.03^{\mathrm{a}}$ & $7.03 \pm 0.01^{\mathrm{b}}$ & $6.60 \pm 0.49^{\mathrm{c}}$ \\
\hline Barley bran & $7.25 \pm 0.06^{\mathrm{a}}$ & $6.49 \pm 0.64^{\mathrm{b}}$ & $6.01 \pm 0.04^{\mathrm{c}}$ \\
\hline Millet bran & $7.96 \pm 0.02^{\mathrm{a}}$ & $6.48 \pm 0.68^{\mathrm{b}}$ & $6.04 \pm 0.15^{\mathrm{b}}$ \\
\hline
\end{tabular}

* Values are mean \pm SD for replicate independent runs.

**Values that bear different superscript letter in the same raw are significantly different at $\mathrm{p}<0.05$.

Table.2 Reducing sugar during refrigeration storage of fermented goat milk supplemented with inulin and different cereal bran

\begin{tabular}{|c|l|c|c|}
\hline Type of supplementation & \multicolumn{3}{|c|}{ Storage period (weeks) } \\
\cline { 2 - 4 } & \multicolumn{1}{|c|}{ O (Initial) } & One & Two \\
\hline Inulin & $1.35 \pm 0.01^{\mathbf{a}}$ & $1.32 \pm 0.01^{\mathbf{a}}$ & $1.04 \pm 0.00^{\mathbf{b}}$ \\
\hline Sorghum bran & $1.30 \pm 0.01^{\mathbf{a}}$ & $0.80 \pm 0.00^{\mathbf{b}}$ & $0.59 \pm 0.00^{\mathbf{c}}$ \\
\hline Barley bran & $1.31 \pm 0.00^{\mathbf{a}}$ & $0.59 \pm 0.01^{\mathbf{b}}$ & $0.48 \pm 0.01^{\mathbf{b}}$ \\
\hline Millet bran & $0.87 \pm 0.00^{\mathbf{a}}$ & $0.59 \pm 0.01^{\mathbf{b}}$ & $0.40 \pm 0.00^{\mathbf{b}}$ \\
\hline
\end{tabular}

* Values are mean \pm SD for replicate independent runs.

**Values that bear different superscript letter in the same raw are significantly different at $\mathrm{p}<0.05$.

Table.3 pH during refrigeration storage of fermented goat milk supplemented with inulin and different cereal bran

\begin{tabular}{|c|c|c|c|}
\hline \multirow{2}{*}{ Type of supplementation } & \multicolumn{3}{|c|}{ Storage period (weeks) } \\
\cline { 2 - 4 } & $\mathrm{O}$ (Initial) & One & Two \\
\hline Inulin & $5.11 \pm 0.00^{\mathbf{a}}$ & $4.78 \pm 0.01^{\mathbf{a}}$ & $3.81 \pm 0.01^{\mathbf{b}}$ \\
\hline Sorghum bran & $5.65 \pm 0.01^{\mathbf{a}}$ & $4.27 \pm 0.01^{\mathbf{b}}$ & $3.88 \pm 0.01^{\mathbf{c}}$ \\
\hline Barley bran & $4.40 \pm 0.01^{\mathbf{a}}$ & $4.31 \pm 0.01^{\mathbf{a}}$ & $3.69 \pm 0.00^{\mathbf{b}}$ \\
\hline Millet bran & $4.45 \pm 0.03^{\mathbf{c}}$ & $3.97 \pm 0.02^{\mathbf{b}}$ & $3.84 \pm 0.01^{\mathbf{a b}}$ \\
\hline
\end{tabular}

$*$ Values are mean \pm SD for replicate independent runs.

$* *$ Values that bear different superscript letter in the same raw are significantly different at $\mathrm{p}<0.05$. 
Table.4 TSS during refrigeration storage of fermented goat milk supplemented with inulin and different cereal bran

\begin{tabular}{|c|c|c|c|}
\hline \multirow{2}{*}{ Type of supplementation } & \multicolumn{3}{|c|}{ Storage period (weeks) } \\
\cline { 2 - 4 } & \multicolumn{0}{|c|}{ (Initial) $^{\text {One }}$} & Two \\
\hline Inulin & $13.23 \pm 0.04^{\mathbf{a}}$ & $13.25 \pm 0.01^{\mathbf{a}}$ & $11.61 \pm 0.01^{\mathbf{b}}$ \\
\hline Sorghum bran & $11.70 \pm 0.01^{\mathbf{a}}$ & $10.33 \pm 0.02^{\mathbf{b}}$ & $11.94 \pm 0.02^{\mathbf{a}}$ \\
\hline Barley bran & $13.56 \pm 0.01^{\mathbf{a}}$ & $14.09 \pm 0.01^{\mathbf{a}}$ & $12.51 \pm 0.01^{\mathbf{b}}$ \\
\hline Millet bran & $14.21 \pm 0.01^{\mathbf{a}}$ & $14.44 \pm 0.01^{\mathbf{a}}$ & $12.62 \pm 0.22^{\mathbf{b}}$ \\
\hline
\end{tabular}

$*$ Values are mean \pm SD for replicate independent runs.

$* *$ Values that bear different superscript letter in the same raw are significantly different at $\mathrm{p}<0.05$

Table.5 Moisture during refrigeration storage of fermented goat milk supplemented with inulin and different cereal bran

\begin{tabular}{|c|l|c|c|}
\hline Type of supplementation & \multicolumn{3}{|c|}{ Storage period (weeks) } \\
\cline { 2 - 4 } & \multicolumn{1}{|c|}{$\mathbf{O}^{\text {(Initial) }}$} & \multicolumn{1}{|c|}{ One } & Two \\
\hline Inulin & $86.77 \pm 0.04^{\mathbf{b}}$ & $87.75 \pm 0.01^{\mathbf{a}}$ & $88.40 \pm 0.07^{\mathbf{a}}$ \\
\hline Sorghum bran & $88.50 \pm 0.28^{\mathbf{a}}$ & $88.68 \pm 0.02^{\mathbf{a}}$ & $89.07 \pm 0.02^{\mathbf{a}}$ \\
\hline Barley bran & $86.45 \pm 0.71^{\mathbf{a}}$ & $86.92 \pm 0.07^{\mathbf{a}}$ & $87.50 \pm 0.01^{\mathbf{a}}$ \\
\hline Millet bran & $85.79 \pm 0.01^{\mathbf{b}}$ & $86.57 \pm 0.07^{\mathbf{a}}$ & $87.24 \pm 0.00^{\mathbf{a}}$ \\
\hline
\end{tabular}

*Values are mean \pm SD for replicate independent runs.

$* *$ Values that bear different superscript letter in the same raw are significantly different at $\mathrm{p}<0.05$.

Table.6 Titratable acidity during refrigeration storage of fermented goat milk supplemented with inulin and different cereal bran

\begin{tabular}{|c|l|c|c|}
\hline \multirow{2}{*}{ Type of supplementation } & \multicolumn{3}{|c|}{ Storage period (weeks) } \\
\hline Inulin & $\mathbf{O}$ (Initial) & One & \multicolumn{1}{c|}{ Two } \\
\hline Sorghum bran & $0.65 \pm 0.00^{\mathbf{c}}$ & $0.69 \pm 0.07^{\mathbf{b}}$ & $0.96 \pm 0.01^{\mathbf{a}}$ \\
\hline Barley bran & $0.44 \pm 0.07^{\mathbf{c}}$ & $0.80 \pm 0.00^{\mathbf{b}}$ & $1.06 \pm 0.00^{\mathbf{a}}$ \\
\hline Millet bran & $0.82 \pm 0.00^{\mathbf{c}}$ & $0.96 \pm 0.00^{\mathbf{b}}$ & $1.71 \pm 0.07^{\mathbf{a}}$ \\
\hline & $0.93 \pm 0.00^{\mathbf{d}}$ & $0.95 \pm 0.00^{\mathbf{d}}$ & $1.82 \pm 0.71^{\mathbf{a}}$ \\
\hline
\end{tabular}

$*$ Values are mean \pm SD for replicate independent runs.

**Values that bear different superscript letter in the same raw are significantly different at $\mathrm{p}<0.05$.

pH during refrigeration storage of fermented goat milk supplemented with inulin and different cereal bran

Referring to the result in Table 3 shows, the $\mathrm{pH}$ measurement of different fermented goat milk supplemented with inulin and cereal bran (Sorghum, Barely and Millet) during refrigeration storage. There was significant $(\mathrm{p}<0.05)$ reduction in $\mathrm{pH}$ due to supplementation with inulin and different cereal bran at two weeks of refrigeration (Table 3). The highest $\mathrm{pH}$ reduction in the first week was in fermented goat milk supplemented with sorghum bran $(1.39 \mathrm{pH})$, while the lowest reduction was in one supplemented with barely bran $(0.09 \mathrm{pH})$. While the reductions recorded in the second 
week of refrigeration were $0.98,0.62,0.38$ and 0.13 in fermented goat milk supplemented with inulin, barely bran, sorghum bran and millet bran, respectively. In fact, reduction of $\mathrm{pH}$ is mainly due to the fermentation of sugars (Table 2) and accumulation of acid shown in Table 6. The created condition maintained a relatively acid $\mathrm{pH}$ even in large intestine, thus preventing the proliferation of pathogens causing unfavorable disorders. Nevertheless, it was reported that low $\mathrm{pH}$ and storage temperature are the most important determinations in Bifidobacterium mortality during storage (Sakai et al., 1987). Shah et al., (1995, 2000) also found similar decreases in $\mathrm{pH}$ values during storage of commercial yoghurts containing L. acidophilus and B. bifidum.

\section{Changes in TSS during refrigeration storage of fermented goat milk supplemented with inulin and different cereal bran}

The effect of inulin and cereal bran (Sorghum, Barely and Millet) supplemented to fermented goat milk on TSS during refrigeration was obvious in Table 4. There were significant $(p<0.05)$ increases in TSS of all types of fermented samples under refrigerated storage in the first week, then decreased in the second week; except for product supplemented with sorghum bran (Table 4). The amount of increases in the first week of refrigerated storage of different were $0.53,0.23$, and $0.0 .02 \%$ in fermented goat milk with barely bran, millet bran and inulin, respectively. The increases could be attributed to the breakdown of macrocomponents to simple soluble ones. While in the second weeks the rate decreases were $1.58,1.82$, and $1.64 \%$ in fermented goat milk supplemented with barely bran, millet bran and inulin, respectively. The decreases might be due to slight fermentation of soluble sugars by strain BB536 together with the increases in moisture as a dilution factor (Table 5).

\section{Changes in moisture during during refrigeration storage of fermented goat milk supplemented with inulin and different cereal bran}

By extend storage period moisture content of fermented goat milk supplemented with inulin and different cereal bran (Sorghum, Barely and Millet) was slightly increased (Table 5); due to the reduction in TSS by strain BB536 activity (Table 4). The slight increase in moisture might indicate slow enzymatic activity that break down the macro component into simple and releases of some water. Thus, over all levels of moisture after two weeks refrigeration storage of fermented samples increased as compared to their initial levels at the beginning of the storage (Table 5). This increase in moisture might indicate high enzymatic activity that break down the macro-component into simple and to the release of water.

\section{Changes in titratable acidity during refrigeration storage of fermented goat milk supplemented with inulin and different cereal bran}

Organic acids in fermented dairy products play an important role as natural preservatives and also contribute to the characteristic sensory properties of the product. As natural preservatives, they are known to inhibit certain pathogenic organisms, especially in yogurt (Fernandez-Garcia and McGregor, 1994). Table 6 shows the titratable acidity of different fermented goat milk supplemented with inulin and different cereal bran (Sorghum, Barely and Millet). Titratable acidity of the different fermented samples significant $(p<0.05)$ increased by extended storage period for the two weeks correlating well with the reduction in $\mathrm{pH}$ (Table 3). The rates of titratable acidity increases in the first week refrigeration were $0.37,0.14,0.04$ and $0.02 \%$ in fermented goat milk supplemented 
with sorghum bran, barely bran, inulin and millet bran, respectively. In the second week the titratable acidity increases were even higher recording values of $0.88,0.75,0.28$ and $0.25 \%$ in fermented goat milk supplemented with millet bran, barely bran, inulin and sorghum bran, respectively. Strain BB536 as well as other probiotic Bifidobacterium produces lactic acid, acetic acid, hydrogen peroxide, and bactericides are known to inhibit the development of pathogenic bacteria. It was also reported that lactic acid and acetic acid in fermented dairy product have antibacterial effect (Bullen et al,. 1976). The presence of organic acids in fermented dairy foods is due to several reasons, including bovine metabolic processes during the production of milk, bacterial growth, hydrolysis of milk fat or direct addition of acidulants. They are important indicators of bacterial metabolic activity in fermented dairy products like cheese and yogurt, and they also contribute to the taste and flavor of the product along with other volatile and semi-volatile compounds such as diacetyl and acetaldehyde (Marsili et al., 1981; Panari, 1986; Bevilacqua and Califano, 1989; Monnet et al., 1994).

In conclusion the sufficient numbers of viable strain BB536 were maintained in different types of fermented goat milk supplemented with inulin and different cereal bran (sorghum, barely and millet) during refrigeration storage. These viable numbers of the strain after two weeks refrigeration fulfill probiotic food requirements. Therefore, this study can facilitate the development of cereal bran that exerts better viability maintenance as inulin even better during refrigeration of fermented goat milk.

\section{References}

Akalin AS. Fendery S.AK bulut N. (2004). Viability and activity of bifidobacteria in Yoghurt containing fructose oligo saccharine during refrigerated storage. International J. Food Sci. Technol. 39:613-621.

AOAC. (1990). Official Methods for Analysis (15th ed). Association of Official Analytical Chemists. Washington, D.C., USA.

AOAC. (2006). Association of Official Analytical Chemists. Official Methods of Analysis, 17th ed. Arlington, Virginia, USA.

Bevilacqua, A.E., Califano, A.N. (1989). Determination of organic acids in dairy products by high performance liquid chromatography. J. Food Sci. 54:10761079.

Bullen, C.L., Tearle, P.V., Willis, A.T.(1976). Bifidobacteria in the intestinal tract of infants: as in-vivo study. $\mathbf{J}$ Med Microbial.9:325- 333.

Chou, C.C., Hou, J.W. 2000. Growth of bifidobacteria in soymilk and their survival in the fermented drink during storage. Int. J. Food Microbial.,6: 113 121.

Desjardins, M. L., Roy, D., Toupin, C., \& Goulet, J. (1990). Uncoupling of growth and acids production in Bifidobacterium ssp. Journal of dairy science 73(6): 14781484.

Fuller, R. Gibson, G.R. (1997). Modification of the intestinal microflora using probiotics and probiotics. Scand. Journal of Gastoenterology, 222, 28S-31S.

Fernandez-garcia, E., Mcgregor, J.U. (1994). Determination of organic acids during the fermentation and cold storage of yogurt. J. Dairy Sci. 77: 2934-2939.

Haenlein GFW. (2002). Relationship of somatic cell counts in goat milk to mastitis and productivity. Small Rumin Res 45:16378.

Kabeir, B.M., Abd Aziz, S., Muhamed, M., Yazid, A.M. (2005). Growth of Bifidobacterium longum BB536 in Media (fermented cereal porridge) and their survival during storage. let. Appl. Microbial41: 12-131.

Kohimeler, L. (1993). Ern; jhrungsabh; jngige 
Krankheiten und ihre. Kosten. Schriftenreihhe des BMFG, Bd. 27, Nomos Veriag-Ges..

Kojima, T., Yaeshima, T., Ishibashi, N., Shimamura, S., Hayasawa, H. (1996). Inhibitory effects of human-derived bifidobacterium on pathogenic Escherichia coli serotype O-111. Bioscience Microflora 15(1): 17 - 22

Kouane, D., Zhang, G., Chen, J. 2005. Peanut milk and peanut milk based products production. A review. Critical Reviews in Food Science and Nutrition 45:405-423.

Laroia, S., and Martin, J.H. (1991). Methods for enumerating and propagating bifidobacteria. Cultured dairy products Journal 26:32 - 33 .

Marsili, R.T., Ostapenko, H., Simmons, R.E.. Green, D.E.(1981). High performance liquid chromatographic determination of organic acids in dairy products. J. Food Sci. 46: 52-57.

MINITAB statistical software, Release 16 for windows, 2006, minitabInc, USA..

Modler, H.W., Mckellar, R.C., Yaguchi, M. (1990). Bifidobacteria and bifidogenic factors. Canadian Institute of Food Science 23: 29 - 41.

Mohamed, L.H., Kabeir, B.M., Mustafa, S.A., Ibraheem, SE. (2020). Prebiotic effect of different cereal bran (sorghum, barely and millet) on growth of Bifidobacterium longum BB536 during fermentation of goat milk. International Journal of Current Microbiology and Applied Sciences 9 (10): ISSN: 2319-7692 (Print)
ISSN 2319-7706.

Monnet, C., Schmitt, P., Divies, C. (1994). Method for assaying volatile compounds by headspace gas chromatography and application to growing starter cultures. J. Dairy Sci. 77: 1809 - 1815.

Namba , K., Yaeshima, T., Ishibashi, N., Hayasawa, H., Yamazaki, S. (2003). Inhibitory of Bifidobacterium longum on inter hemorrhagic Escherichia coli O157: H7. Bioscience Microflora 22: 85 - 91.

Panari, G. (1986). HPLC of organic acids: an approach to cheese analysis. Milchwissenschaft 41: 214-216.

Richards, L.A. (1968). Diagnosis and improvement of saline and alkaline soil. $1^{\text {st }}$ Ed. IBH Publishing Co., New Delhi, India. Agri. Handbook No. 60.

Sakai, K., Mishima, C., Tachiki, T., Kumagai, H., Tochikura, T. (1987). Mortality of bifidobacteria in boiled yoghurt. J. Ferment. Tech., 65: 215220.

Schneider, W.J., Beisiegel, U., Goldstein, J. L, and Brown, M.S., (1982). Purification of the low density lipoprotein receptor, an acidic glycoprotein of 164,000 molecular weight. J. Biol chem. 257:2664 - 2673.

Shah, N.P. (1997). Bifidobacteria: Characteristics and potential for application in fermented milk products. Milchwissenschaft 52: $16-18$.

Tamime, A.Y., Robinson, R.K. (1985). Yoghurt: Science and technology. Pergamon Press Ltd., Oxford, UK.

\section{How to cite this article:}

Limia Hashim Mohamed, Barka Mohammed Kabeir, Salma Elghali Mustafa, Salma Elzen Ibraheem and Saeed Abdullah Badahdah. 2020. Probiotic Bifidobacterium longum BB536 Viable Existence at Refrigeration Storage of Fermented Goat Milk Supplemented with Inulin and Different Cereal Bran (Sorghum, Barely and Millet). Int.J.Curr.Microbiol.App.Sci. 9(10): 2109-2118. doi: https://doi.org/10.20546/ijcmas.2020.910.257 